\title{
MIGUEL ÁNGEL SOTO ARENAS
}

\section{(12 DE JULIO DE 1963 - 27 dE AGOSTO de 2009)}

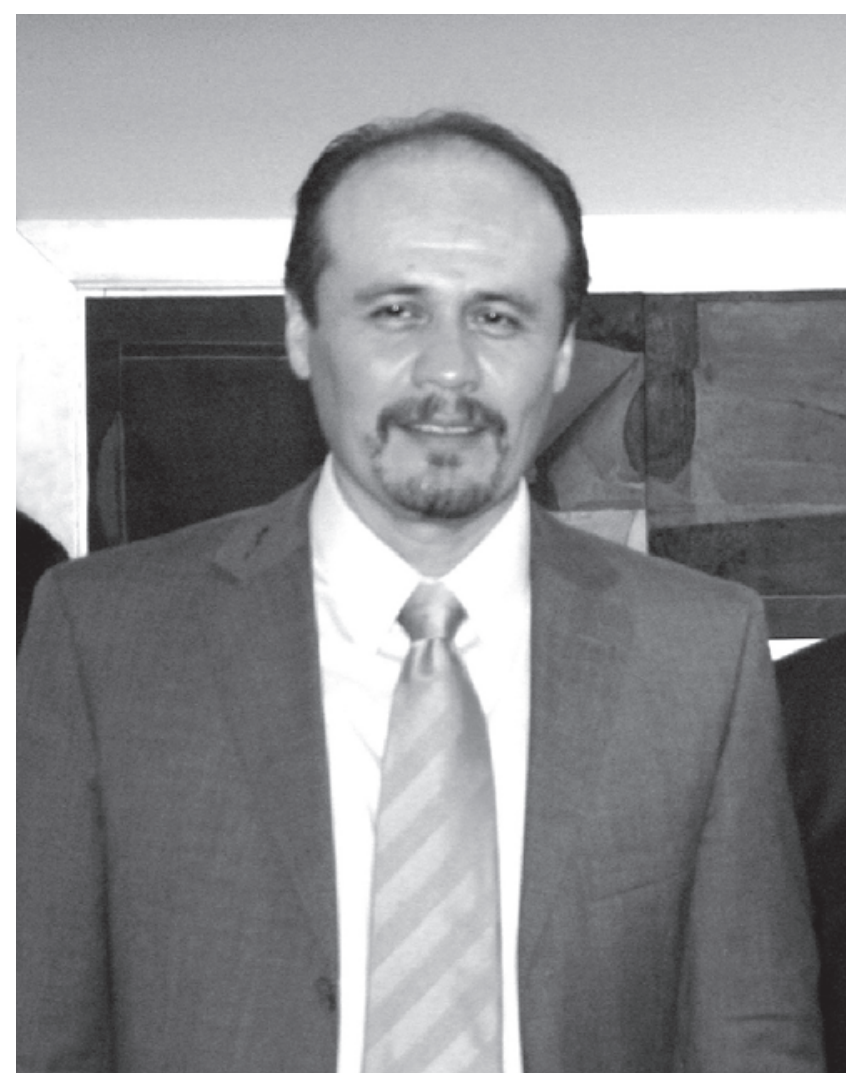

Niguel Ángel Soto nació en la ciudad de Torreón, Coahuila, el 12 de julio de 1963. En esa ciudad cursó sus estudios de primaria y secundaria en el Colegio Cervantes (1969-1978) mientras que la preparatoria la estudió en la Universidad Autónoma del Noreste (1978-1980). A la par de sus primeros estudios, Miguel Ángel se fue involucrando en el mundo de las plantas. Sus padres tenían una gran afición por ellas y él heredó gran parte de esta cultura. Viviendo en una región semiárida le permitió conocer de cerca a las cactáceas y a las suculentas que fueron unos de sus grupos predilectos de plantas y de los cuales tuvo un amplio conocimiento. No obstante de vivir en el desierto, Miguel Ángel ya conocía y cultivaba a sus plantas favoritas, las orquídeas. A su casa llegaban numerosas visitas e incluso reporteros de los medios locales de comunicación para ver su cultivo de orquídeas.

Posteriormente, Miguel Ángel migró a la ciudad de México para realizar sus estudios universitarios; allí cursó la carrera de Biología, en la Facultad de Ciencias de la Universidad Nacional Autónoma de México de 1982-1987. Al terminar los créditos comenzó a trabajar con su tesis de licenciatura sobre las orquídeas de Bonampak, Chiapas. Cabe señalar que en esos tiempos Bonampak era un sitio muy remoto, de difícil acceso y con grandes extensiones de la muy poco conocida Selva Lacandona. De ese sitio, Miguel Ángel y Jorge Meave tuvieron que salir huyendo ante las apocalípticas escenas generadas por el volcán El Chichón (o Chichonal). Miguel Ángel era un perfeccionista y, quizá por ello no terminó esa tesis de licenciatura, aunque sí publicó un artículo sobre esa estancia en el corazón de la Selva Lacandona [Soto Arenas, M.A. 1986. Orquídeas de Bonampak, Chiapas. Orquídea (Méx.) 10:113-132]. Miguel obtuvo el título de biólogo tiempo después con un tema de tesis nuevo, en esta ocasión sobre el género Lepanthes. La tesis la realizó junto con Gerardo Salazar, y este trabajo sirvió de base para la publicación del libro "El género Lepanthes Sw. en México", en el que publicaron 32 nuevas especies y con ello duplicaron el número de especies conocidas para México.

Durante el tiempo que transcurrió entre que él terminó sus estudios de licenciatura y que culminó su tesis, Miguel Ángel desarrolló numerosos proyectos y publicaciones con orquídeas. En ese período, Miguel se pasaba los días entre el Laboratorio de Ecología (Facultad de Ciencias, UNAM), el herbario AMO (desde que este se inauguró, en La Herradura, Estado de México), y en sus innumerables viajes al campo. También viajó a los principales herbarios de los Estados Unidos y Europa, revisando todo el material mexicano de orquídeas. Estos viajes fueron muy fructíferos, sobre todo en la búsqueda de los ejemplares tipo de numerosas especies mexicanas. 
Miguel impartió algunos cursos de licenciatura de la carrera de Biología, en la Facultad de Ciencias, UNAM. Entre ellos: Biogeografía en 10 ocasiones (de 19831993), Ecología General dos veces (1987-1988), Sistemática (1999), y Recursos Naturales (2000-2001). También fue profesor de las biologías de campo: "Fitogeografía del Bosque Mesófilo de Montaña de la Sierra Madre del Sur de Guerrero" (19831984) y "Análisis Sinecológico del Bosque Mesófilo de Montaña del Parque Estatal de Omiltemi, Guerrero." (1984-1985). Dirigió o codirigió alrededor de diez estudiantes tanto de licenciatura como de posgrado. Algunos de ellos recibieron reconocimientos por la calidad de sus tesis, como Rodolfo Solano Gómez cuya tesis "El Género Stelis Sw. (Orchidaceae: Pleurothallidinae) en México" (E.N.E.P. Iztacala, UNAM, realizada en 1993 en co-dirección con E. Hágsater, Herbario AMO) quien obtuvo una mención honorífica en el Certamen de Tesis de Licenciatura de la Sociedad Botánica de México. De forma similar, Mariana Hernández Apolinar recibió el primer lugar del Certamen de Tesis de Licenciatura de la Sociedad Botánica de México con la tesis "Dinámica poblacional de Laelia speciosa (HBK) Schltr. (Orchidaceae)" (Facultad de Ciencias, UNAM, realizada en 1992 en Co-dirección con Irene Pisanty).

En octubre de 1993, Miguel Ángel organizó el V Encuentro Latinoamericano de Orquideología en Xalapa, Veracruz, con la participación de los más connotados especialistas y estudiosos de las orquídeas de América tropical. En este evento también se realizó un importante exposición de orquídeas del cual fue presidente del Comité Organizador (Exporquídea Xalapa '93). Miguel Ángel fue vicepresidente de la Comisión Latinoamericana de Orquideología (C.L.O., 1991-1993) y presidente de la misma en 1993.

Miguel Ángel ingresó al Posgrado en Ecología del Instituto de Ecología en 1994, cursando todos los créditos y aprobando el examen de candidatura de doctorado. Sin embargo, su perfeccionismo hizo que pospusiera la realización de su examen de grado hasta que tuviera las publicaciones que él consideraba como necesarias. La tesis que desarrollaba se titulaba "Evolución en Vanilla (Orchidaceae): filogenia, biogeografía y evolución de caracteres" y la realizaba bajo la dirección de la Dra. Elena Álvarez-Buylla (Laboratorio de Genética Molecular y Evolución, Instituto de Ecología, UNAM). Los estudios de la vainillas de Miguel Ángel no se limitaban a los aspectos mencionados en el título de su tesis, ya que también estudió la diversidad, la variación genética, y los usos de las vainillas. De este trabajo se derivaron interesantes resultados, como el de las rutas y fechas de la dispersión humana de los cultivares de Vanilla planifolia por todo el mundo. Lamentablemente no pudo terminar la descripción formal de varias especies y variedades nuevas que de este género, como Vanilla costaricensis (inéd.), V. cribbiana (Ined), V. dessleri (inéd.), V. sarapiquensis (inéd.) y V. pompona subsp. grandiflora (Lindl.) Soto Arenas (inéd.).

Miguel Ángel fue uno de los más grandes conocedores de la orquideoflora de México y, en general, de toda América tropical. Describió, sólo o como coautor, muchas especies nuevas de orquídeas, entre muchas otras están: Phragmipedium xerophyticum, Barkeria fritz-halbingeriana, Rossioglossum hagsaterianum, Sobralia macdougallii, Stanhopea dodsoniana, S. whittenii, Stelis greenwoodii, Elleanthus teotepecensis, Encyclia calderoniae, E. rzedowskiana, Oncidium leleui. Además, formalizó la sistematización intraespecífica de Laelia anceps y reclasificó (sólo o como coautor) numerosas especies de diferentes géneros, entre ellos Barkeria, Elleanthus, Rhynchostele, Prosthechea y Dichromanthus. Él tenía amplios conocimientos de las Pleurothallidiinae (Stelis, Acianthera, Pleurothallis). Entre descripciones nuevas y reclasificaciones de algunas ya publicadas, de acuerdo con la base de datos del Missouri Botanical Garden (W3TROPICOS), existen más de 160 especies y subespecies descritas por él.

Miguel recolectó más de 11,000 ejemplares de plantas en México, Guatemala, Costa Rica, Panamá y Brasil, los cuales incluyen cerca de 150 ejemplares tipo. El juego principal de sus colectas está depositado en el Herbario AMO (Instituto Chinoín, México, D.F.). Miguel era un incansable viajero y pocas personas conocieron a los 
hábitats naturales de las orquídeas como él. Esta es una de las razones por las cuales fue unos de los autores que colaboró más profusamente en el libro Las Orquídeas de México, del cual supervisó personalmente de su diseño y edición; la obra describe un paseo por los ecosistemas de México y sus orquídeas. Junto con el Catálogo digital (CD) de Las Orquídeas de México es obra de divulgación más completa que existe sobre las orquídeas nacionales.

Uno de sus trabajos ya clásicos fue la publicación "Listado actualizado de las orquídeas de México. Orquídea (Méx.) 11: 231-275 (1989)". Esta lista es la base de las listas más recientes sobre las orquídeas de México. Además, junto con Federico Halbinger fue el autor del libro Laelias de México, que trata sobre uno de los géneros más cultivados por los aficionados a las orquídeas. Miguel Ángel fue editor ejecutivo de la revista Orquídea (Méx.) desde 1985 a la fecha. También fue editor de algunos volúmenes de los Icones Orchidacearum, que es quizá la mejor referencia técnica de las orquídeas mexicanas. Tenía dos volúmenes más en preparación.

De manera adicional, Miguel Ángel colaboró con varios de los grandes orquideólogos actuales como Robert Dressler, Gerardo Salazar, Eric Hágsater, Germán Carnevali, Mark Chase, Cássio van den Berg y Mark Whitten, entre muchos otros. Las publicaciones de Miguel son referencia obligada para los estudiosos de las orquídeas, pero también son de gran utilidad para los biogeógrafos y los evolucionistas de la flora del neotrópico. Debido a su gran labor como botánico, se le han dedicado varias especies en su honor como: Lepanthes sotoi Archila, Maxillaria sotoana Carnevali et Gómez-Juárez, Mormodes sotoana Salazar y Stelis sotoana R. Solano.

Miguel fue un gran conservacionista desde temprana edad; por ejemplo, fue uno de los estudiantes más participativos en la creación de la Reserva del Pedregal de San Ángel (en la Ciudad Universitaria, México, D.F.). En fechas más recientes publicó uno de los trabajos más completos sobre la situación actual de la conservación de orquídeas en México y participó en muchos foros relacionados con la conservación de las orquídeas. Fue un destacado miembro de "Orchid Specialist Group, Species Survival Commission, IUCN" (993-1997; 1998-2009) y miembro del "Conservation exsitu Committee" de la misma comisión (2000-2003). También participó como asesor para diversas dependencias gubernamentales como SARH, SEDESOL, SEMARNAT y CONABIO, estableciendo los criterios más importantes para las estrategias nacionales de la conservación de las orquídeas de México.

Miguel Ángel fue un botánico que amaba a las plantas, y eso se reflejaba en su muy buen cultivo de diversos grupos, entre los que destacan las cactáceas, las cicadáceas y por supuesto las orquídeas. Él logró formar la colección de plantas vivas más importante de especies mexicanas. A partir de las plantas cultivadas y de los ejemplares de campo, él ayudó a formar un banco de DNA para investigación en biología molecular de cerca de 500 especies de orquídeas y otras 500 de Vanilla.

En colaboración con E. Hágsater y Cássio van den Berg, Miguel trabajaba en la preparación de una filogenia del género Epidendrum basada tanto en datos moleculares como morfológicos y de la arquitectura vegetativa; para ello contaba con más de 300 especies de todo el neotrópico secuenciadas.

Miguel destacó por su actitud siempre de colaboración con aficionados y otros biólogos, lo que le llevó a compartir sus conocimientos en sus viajes al campo, en numerosas sesiones de la Asociación Mexicana de Orquideología, y con campesinos, particularmente los cultivadores de vainilla de los estados de Veracruz, Oaxaca y Chiapas. Además de las conferencias y seminarios científicos, impartió más de 150 conferencias en universidades, en jardines botánicos y en asociaciones botánicas y hortícolas.

Quienes tuvimos la fortuna de consultar sus bitácoras de campo, pudimos apreciar el conocimiento enciclopédico que tenía sobre la flora y la vegetación de México. Su aguda visión le permitía encontrar orquídeas aun manejando el automóvil a gran velocidad o entre las ramas en medio de la penumbra de los bosques más cerrados. 
Cabe señalar que él funcionaba como un altímetro humano, pues podía calcular con gran exactitud la altitud a la que nos encontrábamos con sólo mirar la vegetación que nos rodeaba.

Su lamentable deceso ocurrió el 27 de agosto, en Torreón, Coahuila. Miguel Ángel Soto fue un personaje controvertido, pero sin duda fue un ser fuera de serie que deja un gran vacío que será muy difícil de llenar.

Eduardo A. Pérez García

Facultad de Ciencias, UNAM

Eric Hágsater

Herbario AMO, Instituto Chinonín 